\title{
Curcumin sensitizes human gastric cancer cells to 5 -fluorouracil through inhibition of the NFKB survival-signaling pathway
}

This article was published in the following Dove Press journal:

OncoTargets and Therapy

5 December 2016

Number of times this article has been viewed

\author{
Yanting Kang ${ }^{1,2, *}$ \\ Wanle $\mathrm{Hu}^{3, *}$ \\ Encheng Bai ${ }^{1,2}$ \\ Hailun Zheng' \\ Zhiguo Liu' \\ Jianzhang $\mathrm{Wu}^{\prime}$ \\ Rong Jin ${ }^{2}$ \\ Chengguang Zhao' \\ Guang Liang'
}

'Chemical Biology Research Center, School of Pharmaceutical Sciences, ${ }^{2}$ Department of Epidemiology, First Affiliated Hospital, ${ }^{3}$ Department of Coloproctology, Second Affiliated Hospital, Wenzhou Medical University, Wenzhou, Zhejiang, China

*These authors contributed equally to this work

\begin{abstract}
Fluorouracil (5-FU) is the most commonly used chemotherapeutic agent for gastric cancer (GC). However, the occurrence of resistance to 5-FU treatment poses a major problem for its clinical efficacy. In this study, we found that the NFאB-signaling pathway can mediate 5-FU resistance in GC cells. We developed a 5-FU-resistant GC cell line named SGCR/5-FU and found that the 5-FU-induced resistance increased cytosolic I $\mathrm{KB} \alpha$ degradation and promoted $\mathrm{NF} \kappa \mathrm{B}$ nuclear translocation in GC cells. These findings were further confirmed by the activation of the NFKB survival-signaling pathway in clinical specimens. Curcumin, a natural compound, can reverse 5-FU resistance and inhibits proliferation in GC cells by downregulating the NFKBsignaling pathway. Moreover, it can also decrease the expression level of TNF $\alpha$ messenger RNA. Flow cytometry and Western blot analysis results showed that the combination of curcumin and 5-FU caused synergistic inhibition of growth and induction of potent apoptosis in the resistant cancer cell lines in vitro. In conclusion, our results demonstrate that the combination of 5-FU and curcumin could be further developed as a potential therapy for human GC.
\end{abstract}

Keywords: 5-FU, curcumin, $\mathrm{NF \kappa B}$, drug resistance, gastric cancer

\section{Introduction}

Gastric cancer (GC) is the fourth most common type of cancer and the second highest cause of cancer-related death worldwide. ${ }^{1}$ Fluorouracil (5-FU) has been used as the standard of care for advanced GC and has been found to increase overall survival by $6 \%$ and reduce the risk of mortality by $18 \% .{ }^{2}$ However, as most patients relapse with lethal drug-resistant disease, the efficacy of 5-FU for GC is limited in clinical treatment. ${ }^{3}$ To overcome 5-FU resistance, a combined therapy of docetaxel, cisplatin, and 5-FU has been developed and has demonstrated improved efficacy, particularly for advanced GC. ${ }^{4}$ However, it is very difficult to deal with intrinsic or acquired resistance of certain tumors in 5-FU therapy. Furthermore, the increased toxicity of the aforementioned combination therapy reduces patients' ability to tolerate the chemotherapy regimen. Currently, the precise mechanisms for 5-FU resistance in $\mathrm{GC}$ remain elusive. Therefore, identifying mechanisms underlying the drug resistance is essential for developing novel approaches to improve the clinical outcome of 5-FU therapy. We hypothesize that combination therapies targeting specific cellular pathways may provide a rationale to abrogate resistance and decrease the toxicity of chemotherapy for a better long-term outcome in GC treatment.

$\mathrm{NF \kappa B}$, a transcription factor, typically exists as a heterodimeric complex composed

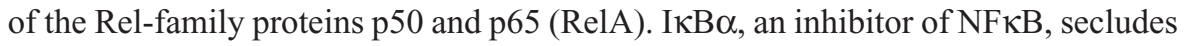


the p65-p50 heterodimer in the cytoplasm under the inactive condition. Once the cell is provoked, stimulus-mediated phosphorylation of $\mathrm{I} \kappa \mathrm{B} \alpha$ and subsequent proteolytic degradation cause the release and nuclear accumulation of RelA-p50 dimer, where it binds to specific promoters and subsequently regulates carcinoma-related gene transcription. ${ }^{5}$ Tumor necrosis factor alpha (TNF $\alpha$ ) has long been known to induce NFKB signaling. It is also an intricate linker between inflammation and cancer through mediating the process of apoptosis and cell-mediated immunity. ${ }^{6}$ In a previous study, upregulation of TNF $\alpha$ transcription was shown specifically to promote tumor progression in some human tumors. ${ }^{6,7}$ Highly metastatic tumor cells could be rescued from apoptosis by activating autocrine TNF $\alpha$. Another study has also ascribed intrinsic drug resistance to production and secretion of TNF $\alpha$ by cancer cells. ${ }^{8}$ It has been reported that the aberrant production of TNF $\alpha$ may also induce chemoresistance. ${ }^{7}$

The transcription factor NFKB has also been linked with many functions. ${ }^{9-12}$ Moreover, owing to constitutive NFאB activity conferring resistance to gemcitabine in pancreatic carcinoma and paclitaxel in prostate cancer, ${ }^{9,13}$ several treatment strategies have been applied to block NFкB signaling as a new adjuvant approach in chemotherapy. These findings suggest that NFKB inhibitors could reduce chemoresistance and may be used in combination with chemotherapeutic drugs as a novel therapy for GC.

Curcumin, a natural compound from turmeric, has an excellent safety profile. It has been found to have antitumor, anti-inflammatory, and apoptotic properties both in vitro and in vivo. ${ }^{14-16}$ Studies have demonstrated that curcumin has the potential to be combined with chemotherapeutics for GC. ${ }^{17,18}$ These reports focused mainly on the role of curcumin in resistant GC cells through the activation of survivin and STAT3 signaling. In recent clinical trials, the combination of curcumin and standard docetaxel chemotherapy has demonstrated significant clinical improvements in patients with advanced breast cancer and castration-resistant prostate cancer. ${ }^{19,20}$ However, a 5-FU and curcumin combination treatment for resistant GC cells has not been tried in clinical trials. In this study, we attempted to investigate whether curcumin could inhibit activation of the NFкB survival-signaling pathway to reverse GC resistance and enhance the efficacy of 5-FU chemotherapy. Our results showed that the combination of 5-FU and curcumin caused markedly synergistic inhibition of growth and induction of apoptosis in SGC and SGCR/5-FU cell lines. Further study of the underlying mechanism indicates that curcumin may overcome 5-FU resistance in GC cells by downregulating the
NFאB-signaling pathway. The results may provide a rationale for further development of a 5-FU and curcumin combination therapy as a new approach to reverse $\mathrm{GC}$ acquired resistance and induce GC-cell death.

\section{Materials and methods Cell lines, compounds, and reagents}

The human GC cell line SGC-7901 (SGC) was obtained from the Shanghai Institute of Biosciences and Cell Resources Center (Chinese Academy of Sciences, Shanghai, China). The cells were routinely cultured in Roswell Park Memorial Institute 1640 medium (Thermo Fisher Scientific, Waltham, MA, USA) supplemented with 10\% heat-inactivated bovine serum albumin (BSA; GE Healthcare, Little Chalfont, UK) and a $1 \%$ penicillin-streptomycin solution (Thermo Fisher Scientific) in a humidified cell incubator with an atmosphere of $5 \% \mathrm{CO}_{2}$ at $37^{\circ} \mathrm{C}$. Antibodies for I $\mathrm{BB} \alpha$, phosphorylated $\mathrm{I} \kappa \mathrm{B} \alpha(\mathrm{p}-\mathrm{I} \kappa \mathrm{B} \alpha)$, cleaved PARP (cl-PARP; 5625S), Bax (sc-493), Bcl2 (sc-492), and horseradish peroxidase (HRP)conjugated (sc-2313) and phycoerythrin (PE)-conjugated (sc-3755) secondary antibodies antirabbit immunoglobulin $\mathrm{G}$ (IgG)-HRP and antimouse IgG-HRP were purchased from Santa Cruz Biotechnology (Dallas, TX, USA). Antibodies for GAPDH (sc-32233) and cl-caspase 3 were obtained from Cell Signaling Technology (Danvers, MA, USA). HRP-conjugated (sc-2313) and PE-conjugated (sc-3755) secondary antibodies were purchased from Santa Cruz Biotechnology. Dimethyl sulfoxide (DMSO) and MTT were obtained from Sigma-Aldrich (St Louis, MO, USA). 5-FU (F100149) and TNF $\alpha$ were obtained from Shanghai Universal Biotech Company (Shanghai, China), and an annexin $\mathrm{V}$ apoptosis-detection kit I and propidium iodide (PI) were purchased from BD (Franklin Lakes, NJ, USA). Curcumin was purified to $>95 \%$ by recrystallization and silica-gel chromatography. The compound used in vitro was dissolved in DMSO. A Bradford protein-assay kit, polyvinylidene fluoride membrane, and enhanced chemiluminescence kit were obtained from Bio-Rad Laboratories (Hercules, CA, USA). A protease phosphatase-inhibitor mixture was obtained from Applygen Technologies (Beijing, China). Acrylamide (40\%), Coomassie Brilliant Blue, tetramethylethylenediamine, Tris-glycine, sodium dodecyl sulfate, prestained protein marker, and nonfat dry milk were from Bio-Rad Laboratories.

\section{Western blot analysis}

Cells or homogenized tumor tissues were assessed. Thereafter, protein extracts $(80 \mu \mathrm{g})$ were separated on precast 
$4 \%-12 \%$ sodium dodecyl sulfate polyacrylamide-gel electrophoresis gels and then transferred to nitrocellulose membranes (Bio-Rad Laboratories). After being blocked with fresh 5\% nonfat milk in Tris-buffered saline-polysorbate 20 for 1.5 hours at room temperature, the membrane was incubated at $4{ }^{\circ} \mathrm{C}$ overnight with the specific primary antibody and at room temperature for 1 hour with the secondary antibody, followed by three washes. Immunoreactive bands were visualized using the enhanced chemiluminescence kit. The density of the immunoreactive bands was analyzed using ImageJ software (National Institutes of Health, Bethesda, MD, USA).

\section{Immunohistochemistry}

Histological sections $(5 \mu \mathrm{M})$ were deparaffinized and rehydrated. Antigen retrieval was performed by heating the slides in a $10 \mathrm{mM}$ citrate buffer in a pressure cooker. Subsequently, the specimens were washed in $0.01 \mathrm{M}$ phosphate-buffered saline (PBS), treated with 3\% hydrogen peroxide, and washed in $0.01 \mathrm{M}$ PBS again. Blocking was performed with 3\% BSA in $0.01 \mathrm{M} \mathrm{PBS}$, and then the specimens were incubated with the respective reagents overnight at $4^{\circ} \mathrm{C}$. For the detection of the expression of $\mathrm{I} \kappa \mathrm{B} \alpha$ protein, anti-I $\kappa \mathrm{B} \alpha$ polyclonal $\mathrm{IgG}$ antibody (1:200; Santa Cruz Biotechnology) was used as a primary antibody, and donkey antirabbit IgG-HRP antibody (1:200; Santa Cruz Biotechnology) was used as a secondary antibody. Thereafter, these slides were stained with diaminobenzidine (Beyotime, Haimen, China) and counterstained with hematoxylin. Sections $5 \mu \mathrm{m}$ thick containing both tumor and normal tissues taken from each patient were used for $\mathrm{I} \kappa \mathrm{B} \alpha$ immunohistochemistry.

\section{Immunofluorescent staining}

Cells were grown on sterilized coverslips in a six-well dish overnight. Cells were fixed with $4 \%$ paraformaldehyde for 10 minutes, washed with PBS, and blocked with 3\% BSA for 1 hour at room temperature. All cell preparations were incubated with the primary antibodies against p65 (1:200) overnight at $4^{\circ} \mathrm{C}$, then PE-labeled goat antirabbit antibody (1:400) IgG was used as a secondary antibody for 1 hour at room temperature. Afterward, nuclei were stained with DAPI. The images were captured with confocal microscopy (400× amplification, Eclipse Ti; Nikon, Tokyo, Japan).

\section{Resistance index and cell viability via MTT assay}

Cells were incubated in 96-well plates with an initial culture medium of $4 \times 10^{3}$ cells per well and cultured with various concentrations of curcumin in 96-well plates for 72 hours. In the combination treatment, drugs (curcumin and 5-FU) were simultaneously added to the culture medium. Cells were treated with an MTT $5 \mathrm{mg} / \mathrm{mL}(20 \mu \mathrm{L}$ per well) solution for 4 hours at $37^{\circ} \mathrm{C}$. After this period, the MTT was carefully aspirated, and formazan crystals were dissolved by adding $150 \mu \mathrm{L}$ of DMSO to each well. The results were analyzed using spectrophotometry at $490 \mathrm{~nm}$ wavelength. Growth inhibition was assayed by MTT, and half-maximal inhibitory concentration $\left(\mathrm{IC}_{50}\right)$ values were calculated by GraphPad Prism 6 software. The resistance index was calculated as the ratio between the $\mathrm{IC}_{50}$ of $\mathrm{SGCR} / 5-\mathrm{FU}$ cells and that of SGC cells.

\section{Development of 5-FU-resistant sublines from the SGC cell lines}

5-FU-treated conditioned media (5-FU-CM) cells collected from fresh SGC cells incubated with 5-FU (5-FU, $10 \mu \mathrm{M})$ for 72 hours were used to prepare SGC-7901R/5-FU (SGCR/5-FU) cell lines. CM cells were added to fresh SGC cells, followed by further 5-FU treatment (low concentrations increased successively) for more than 3 months. ${ }^{21,22}$ This process was monitored by MTT assay at regular intervals. The procedure to develop 5-FU-resistant sublines from SGC cell lines was as follows. Cells were serially passaged initially with low concentrations of 5-FU (about 1/10 $\mathrm{IC}_{50}$, $2 \mu \mathrm{M})$ and sequentially cultured in increasing concentrations of about 1-1.5 $\mu \mathrm{M} 5$-FU every two weekdays. MTT was measured every half a month or month to see the degree of 5-FU drug-resistance changes and at the same time to freeze some drug-resistant cells. Cells that were able to survive stably in the medium containing $10 \mu \mathrm{M}$ of 5-FU were considered to be 5-FU-resistant and named SGCR/5-FU cells. Experiments with these cell sublines were performed and the cells maintained in the 5-FU-free medium for 2-3 weeks.

\section{Clonogenic survival assay}

After being trypsinized, centrifuged, and replenished with fresh media, the cells were prepared for single-cell suspensions (1,000 cells per well) and seeded onto six-well plates, leading to attachment overnight. The next day, cells were treated for 24 hours with inhibitors, as indicated in the figures. After being rinsed with fresh Dulbecco's Modified Eagle's Medium, cells were incubated for 18 days until the colonies were visible. Following treatment, surviving colonies were fixed with $4 \%$ paraformaldehyde and stained with $0.05 \%$ crystal violet for 15 minutes at room temperature. 


\section{Flow cytometry}

Apoptosis was detected by annexin $\mathrm{V}$-fluorescein isothiocyanate and PI double-staining (BD) and assessed by fluorescenceactivated cell sorting. Briefly, SGCR/5-FU cells were incubated on $60 \mathrm{~mm}$ dishes overnight, then treated with drugs for 24 hours, and the cells were collected into tubes. The cells were then stained with annexin V-fluorescein isothiocyanate for 10 minutes and PI for 5 minutes in the dark and detected by fluorescence-activated cell sorting with FACSDiva software.

\section{Preparation of nuclear and cytoplasmic extracts}

SGCR/5-FU cell lines were prepared. Experiments were performed according to manufacturer's instructions (nuclear extraction kit; KeyGen Biotech, Nanjing, China). Protein concentration was determined using the Bio-Rad proteinassay reagent. The nuclear extract (15-30 $\mu \mathrm{g}$ of protein) was used for Western immunoblot analysis.

\section{RNA interference}

Small-interfering RNA (siRNA) pools against NFkB p65 and negative control were purchased from GE Healthcare. Cells were grown to $60 \%$ confluence in six-well plates and transfected with Lipofectamine RNAiMax (Thermo Fisher Scientific) as indicated in the manufacturer's instructions. After incubation for 6 hours at $37^{\circ} \mathrm{C}$, the transfection media were replaced with normal growth media, and the cells were allowed to recover for an additional 24 hours before experimental treatments.

\section{Determination of caspase- 3 activity}

Cellular apoptosis was analyzed with a caspase 3 activity kit (Beyotime).

\section{Real-time quantitative polymerase chain reaction (PCR)}

Total RNA from the tissues and cells was extracted using Trizol reagent (Thermo Fisher Scientific). Reverse-transcription (RT) quantitative PCR was performed with an M-MLV Platinum RT-qPCR kit (Thermo Fisher Scientific). The primers used for real-time PCR to detect TNF $\alpha$ (forward primer 5'-CCCAGGGACCTCTCTCTAATC-3', reverse primer: 5'-ATGGGCTACAGGCTTGTCACT-3') were designed on an iQ5 Multicolor real-time PCR detection system (BioRad Laboratories) and normalized to internal control $\beta$-actin messenger RNA (mRNA).

\section{GC-tumor samples}

The series of 32 clinical GC samples were obtained from the First Affiliated Hospital of Wenzhou Medical University.
Normal gastric tissues that were more than $5 \mathrm{~cm}$ away from the edge of tumors were randomly selected. A cohort of formalin-fixed and paraffin-embedded tissue blocks was prepared. Other tissues were removed and stored in liquid nitrogen for 1 week, then in the freezer to save. Specimens were diagnosed histopathologically and staged according to the Union for International Cancer Control classification system. The collection and analysis of clinical specimens were approved by the Institutional Review Board of The First Affiliated Hospital of Wenzhou Medical University. Informed written consents were obtained from all patients prior to participation.

\section{Statistical analysis}

Significance of correlations was assessed using GraphPad Prism software. Unpaired $t$-tests were used for analysis, assuming Gaussian populations with a $95 \%$ confidence interval. Data are presented as mean \pm standard deviation. Differences were analyzed with Student's $t$-test, and significance was set at $P<0.05$.

\section{Results \\ NFKB signal-pathway activation promotes 5-FU resistance}

We investigated the possible signal pathways responsible for drug resistance to 5-FU chemotherapy for GC. First, we developed a 5-FU-resistant SGCR/5-FU GC cell line by chronically exposing parental cells to increasing doses of 5-FU over 3 months. As shown in Figure $1 \mathrm{~A}$, the $\mathrm{IC}_{50}$ values of 5-FU in SGC and SGCR/5-FU cells were $17.98 \mu \mathrm{M}$ and $341.25 \mu \mathrm{M}$, respectively, and the resistance index of SGCR/5-FU cells was 18.9. Compared with parental SGC cells, SGCR/5-FU cells exhibited significant resistance to 5-FU treatment in vitro. In addition, there were obvious changes in morphology between 5-FU-resistant SGCR/5-FU GC cells and -sensitive SGC cells (Figure 1B). Collectively, these data confirmed that SGCR/5-FU cells had acquired resistance to 5-FU. Next, we investigated whether NFKB was responsible for resistance to 5-FU in SGCR/5-FU cells. We used two different time points for SGCR/5-FU cells (SGCR1 and SGCR2). Immunoblot analysis revealed that the degradation of I $\mathrm{KB} \alpha$ was markedly increased in SGCR/5-FU cells compared with parental SGC cells (Figure 1C and D). Results showed that the transcription factor NFKB was activated under long-term exposure to 5-FU treatment. To confirm this result further, we repeated the immunoblot analysis using three clones of $\mathrm{SGCR} / 5-\mathrm{FU}$ cells. The protein levels of I $\mathrm{KB} \alpha$ in the three resistant SGCR/5-FU cell clones were decreased compared with parental SGC cells 
(Figure 1E and F). Additionally, we found that the nuclear transcription factor NFKB p65 was activated in resistant GC cells (Figure 1G-I). These results indicated that NFאB activation was a major factor that mediated the resistance to 5-FU in GC cells. Then, we sought to elucidate further the role of NFKB p65 as a determinant of therapy response by RNA-interference assay. The proliferation assay showed that knockdown of NFKB p65 by siRNA in SGCR/5-FU cells increased 5-FU sensitivity, as opposed to the cells transfected with the control siRNA (Figure 1J-L).
A

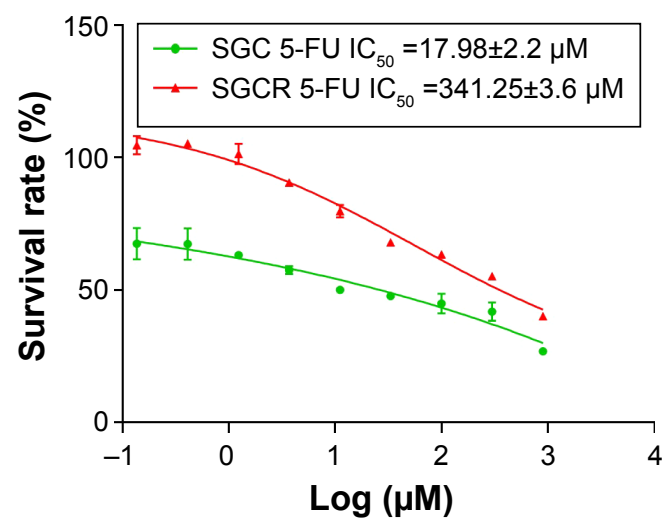

C

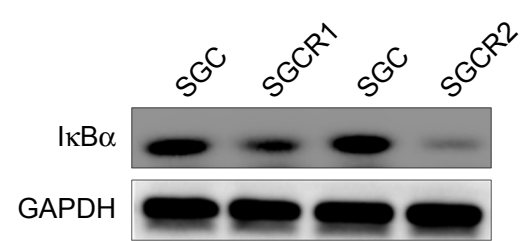

E

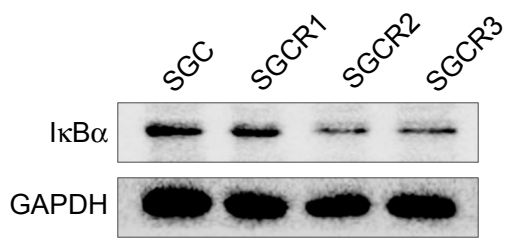

G
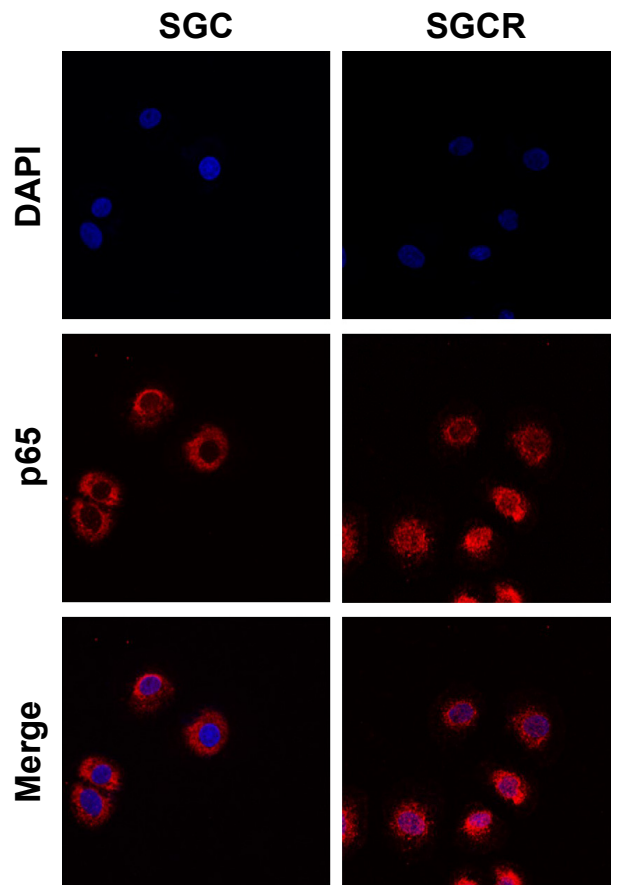

B
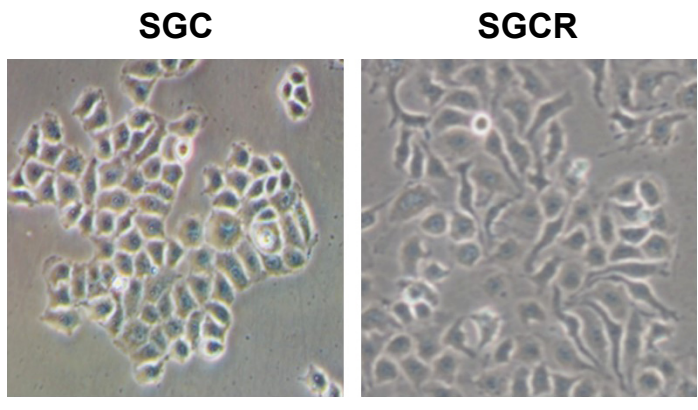

D
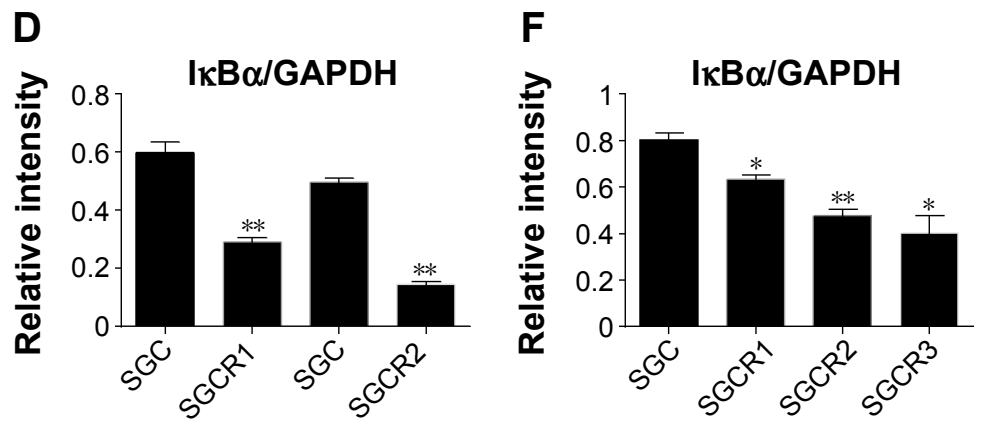

H
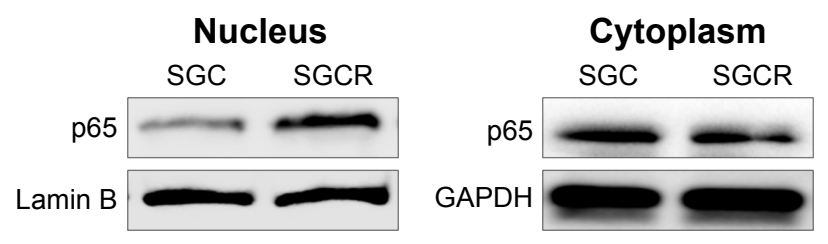

I

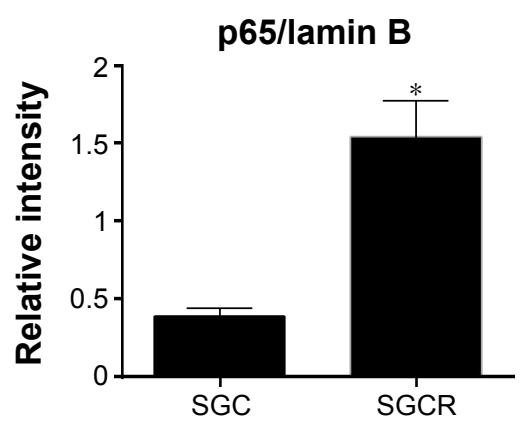

Figure I (Continued) 
$\mathbf{J}$

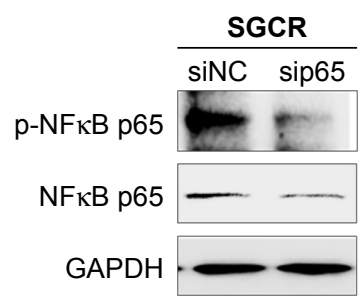

K

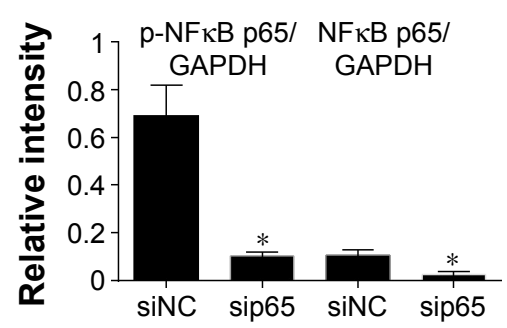

L

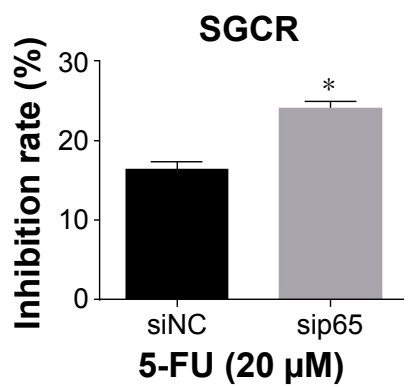

Figure I 5-FU-resistant SGCR cells express constitutively activated NFKB signaling.

Notes: (A) SGC and SGCR cells were treated with escalating concentrations of 5-FU drugs for 3 days. Cell growth was determined by MTT assay, and SGC resistant to 5-FU named SGCR/5-FU (SGCR). (B) Cellular morphology images of SGC and SGCR were taken under the microscope. (C, D) Cells were lysed and subjected to immunoblot analysis with antibodies to IKB $\alpha$. GAPDH was used as an internal control. SGCR/5-FU cells (SGCRI, SGCR2) at two time points were used. SGCRI and SGCR2 represent the 2-month- and 3-month drug-resistant SGCR/5-FU cell lines, respectively. $* * P<0.01$ compared with GAPDH. (E, F) The expression level of I $K B \alpha$ was assessed by Western blot analysis. SGCRI, SGCR2, and SGCR3 represent three clones from 3-month drug-resistant SGCR/5-FU cell lines. $* P<0.05$ compared with GAPDH; **P<0.0I compared with GAPDH. (G) SGC and SGCR were fixed and stained by immunofluorescence using a polyclonal antibody against NFkB p65. The results are the representatives of three or more independent experiments. SGC and SGCR cells were stained with NFKB p65 red fluorescence and DAPI blue fluorescence for detecting the translocation of NFkB p 65 from the cytosol to the nuclear. $(\mathbf{H}, \mathbf{I})$ Nuclear and cytoplasmic extracts were prepared and analyzed by Western blot with antibodies against $N F \kappa B$ p 65 . $* P<0.05$ compared with lamin B. (J-L) MTT assay comparing proliferation of cells with transfection of NC (siNC) or NFKB p65-specific siRNA (sip65) under 5-FU treatment. Data represent similar results from at least two independent experiments. $* P<0.05$.

Abbreviations: 5-FU, fluorouracil; NC, negative control; siRNA, small-interfering RNA; IC ${ }_{50}$, half-maximal inhibitory concentration.

\section{Curcumin overcomes resistance of SGC cells to 5-FU treatment}

Based on significant NFKB activation in 5-FU-resistant SGC cells and the fact that curcumin has been reported to suppress NFKB activation, ${ }^{23}$ we tested whether curcumin could improve the sensitization of SGCR/5-FU cancer cells. We treated SGCR/5-FU-resistant cells with 5-FU, single-agent curcumin, or a combination (5-FU + curcumin), followed by MTT assay. As shown in Figure 2A, curcumin (at $2.4 \mu \mathrm{M}$ ) synergistically increased the efficacy of 5-FU in SGCR/5-FU cells at all 5-FU doses in MTT assays. These data showed that they had strong synergism at least (confidence interval $<0.3$ ). We further investigated whether combination treatment could inhibit colony-formation capability. As shown in Figure 2B, the cancer cells showed a decreased ability to recover and form colonies following combination treatment with 5-FU and curcumin. The results demonstrated a synergistic effect of 5-FU and curcumin. We next examined the synergistic effect of curcumin on apoptosis in the 5-FU-resistant cell lines. The combined treatment with 5-FU and curcumin promoted more upregulation of Bax and cl-PARP compared with treatment with the single agent in SGCR/5-FU cell lines (Figure 2C and D). We further measured the expression and activity of caspase 3 to evaluate the effect of combination treatment of 5-FU and curcumin on apoptosis. The results are shown in Figure 2E, F, and I. Treatment of SGCR/5-FU cells with combined 5-FU and curcumin significantly enhanced apoptotic cell death. In addition, apoptotic cell populations were measured by flow cytometry to analyze their cellular DNA contents after staining with PI and annexin V. The results in Figure 2G and $\mathrm{H}$ show that the combination of curcumin and 5-FU induced more apoptosis in SGCR/5-FU cells than treatment with each drug alone, further suggesting a strong synergistic induction of apoptosis induced by both agents.

\section{Curcumin disrupts the NFKB-signaling pathway}

To investigate the mechanism responsible for activation of NFKB signaling in SGCR cells, we examined the expression of TNF $\alpha$, an important factor involved in NFKB signaling. ${ }^{24}$ Quantitative RT-PCR analysis revealed that the amount of TNF $\alpha$ mRNA was greatly increased in SGCR/5-FU cells compared with parental SGC cells (Figure 3A). We further tested whether CM from 5-FU-treated SGC cancer cells or $\mathrm{CM}$ from cisplatin-treated SGC cells affected I $\mathrm{KB} \alpha$ protein changes in naïve SGC cells. Preincubation of SGC cells with 5-FU-CM or cisplatin-CM significantly increased the degradation of $\mathrm{I} \kappa \mathrm{B} \alpha$ (Figure 3B), indicating that 5-FU-CM and cisplatin-CM may have activated $\mathrm{NF \kappa B}$ signaling. We reasoned that the presence of TNF $\alpha$ secretion in the cell-culture media could have dampened the response of SGC cells to 5-FU. Consequently, we examined the effect of exogenous TNF $\alpha$ in parental SGC cells. We observed that exposure to TNF $\alpha$ induced resistance to 5-FU in SGC cells (Figure 3D), supporting the notion that increased secretion of TNF $\alpha$ can lead to the development of 5-FU resistance.

Next, we investigated the molecular mechanisms underlying the synergic effect of 5-FU and curcumin in SGCR/5-FU cells. We employed Western blot to test whether the NFKBsignaling pathway was involved in the curcumin-mediated 
anticancer effects. As shown in Figure 3E and F, following the exposure to curcumin, the protein level of the degradation of I $\mathrm{I} B \alpha$ decreased significantly in proportion to the dosage of curcumin in SGCR/5-FU cells. The NFkBsignaling pathway has been shown to play an important role in various cancers. ${ }^{25-27}$ Based on the results obtained, we further examined whether curcumin could inhibit the NFKBsignaling pathway in 5-FU-treated SGCR/5-FU cells. As we expected, curcumin efficiently suppressed NFKB activity in SGCR/5-FU cells (Figure $3 \mathrm{G}$ and H). Furthermore, curcumin inhibited activation of the NFKB survival-signaling pathway that resulted from 5-FU-CM (Figure 3I and J). Our data
A

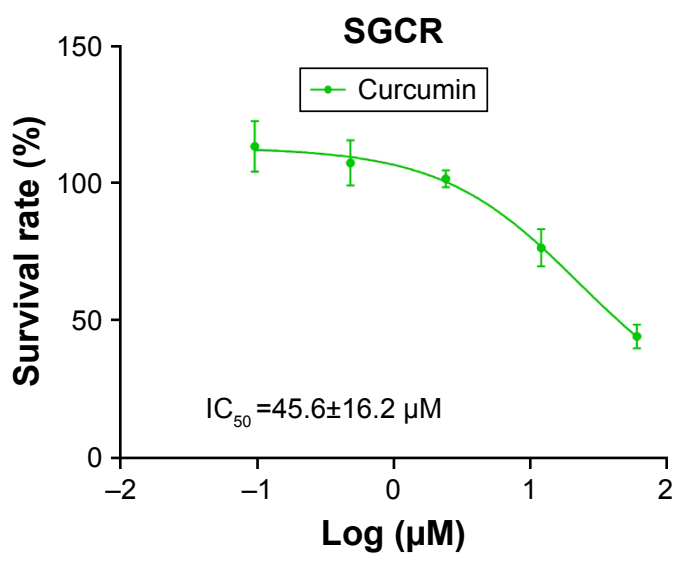

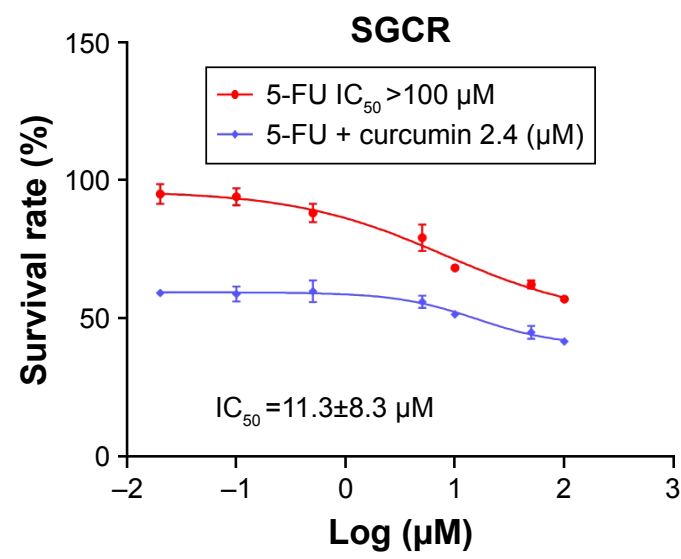

SGCR

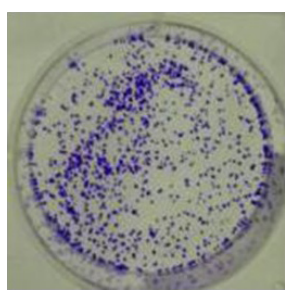

DMSO

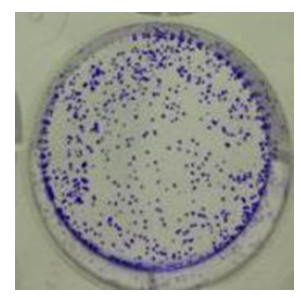

$5-\mathrm{FU} 20 \mu \mathrm{M}$

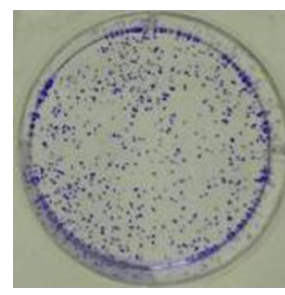

Curcumin $2.5 \mu \mathrm{M}$

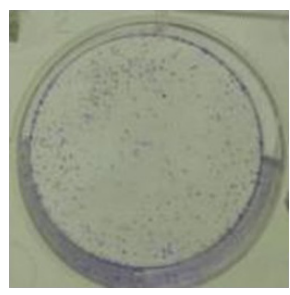

Combination
C

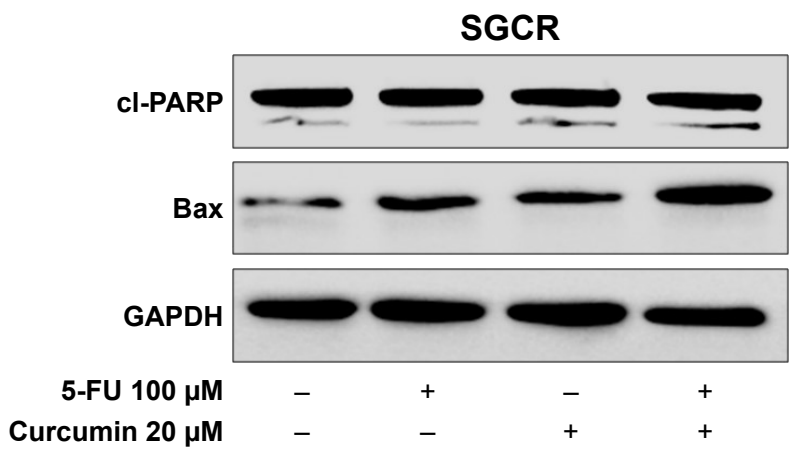

D
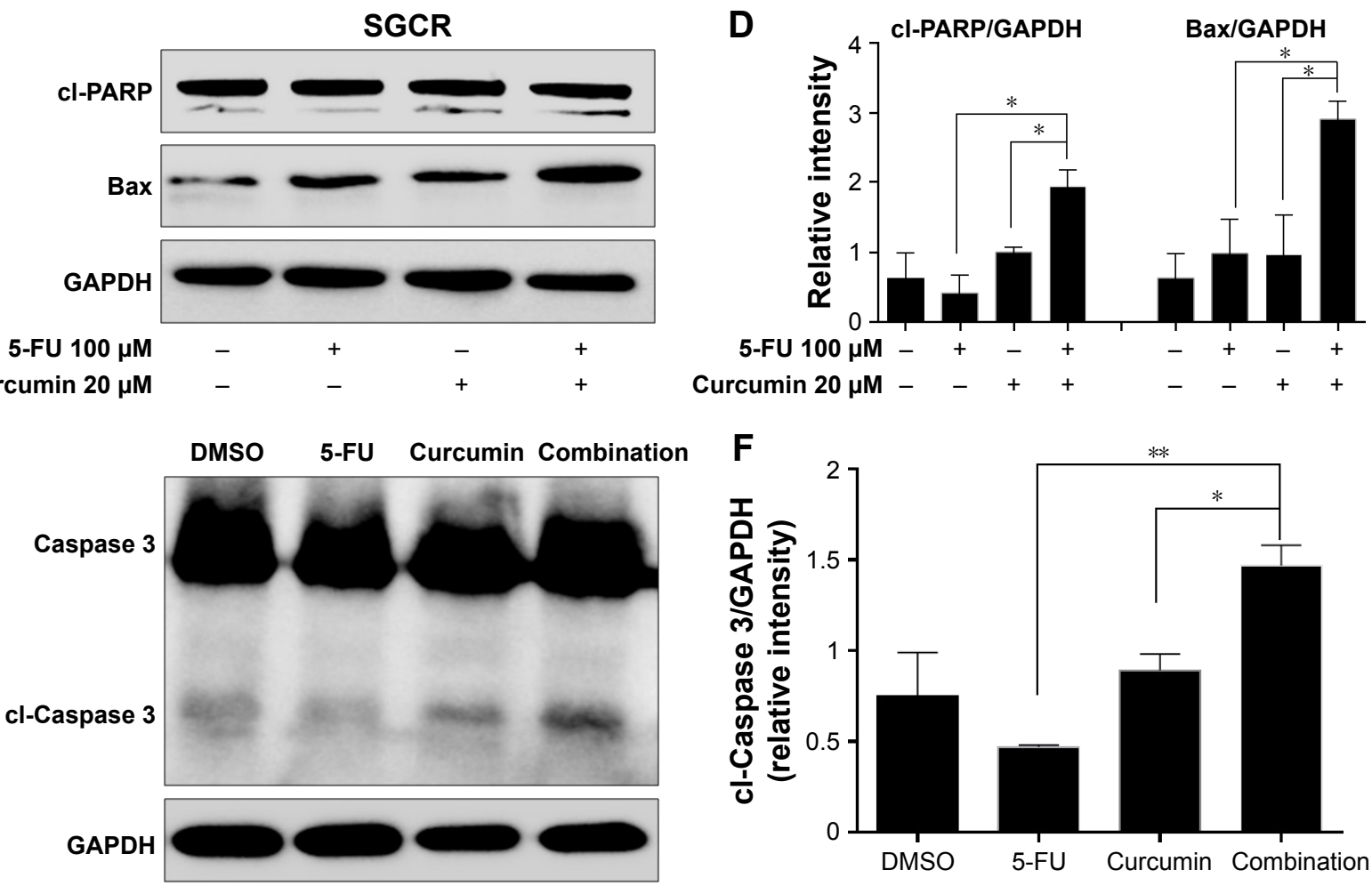

F

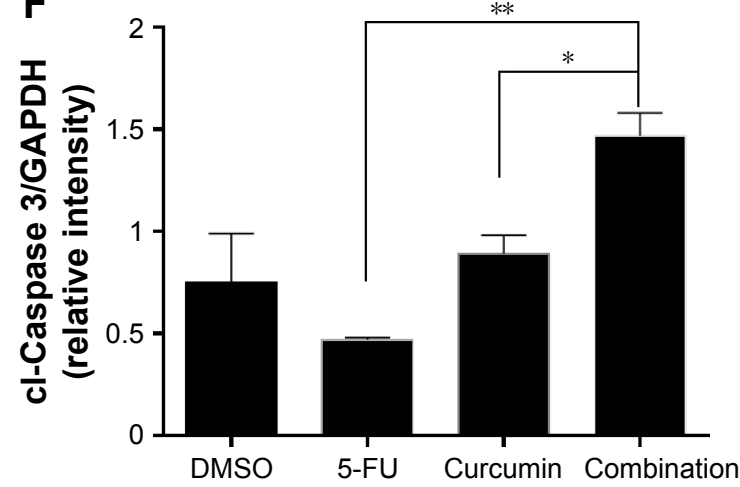

Figure 2 (Continued) 
G
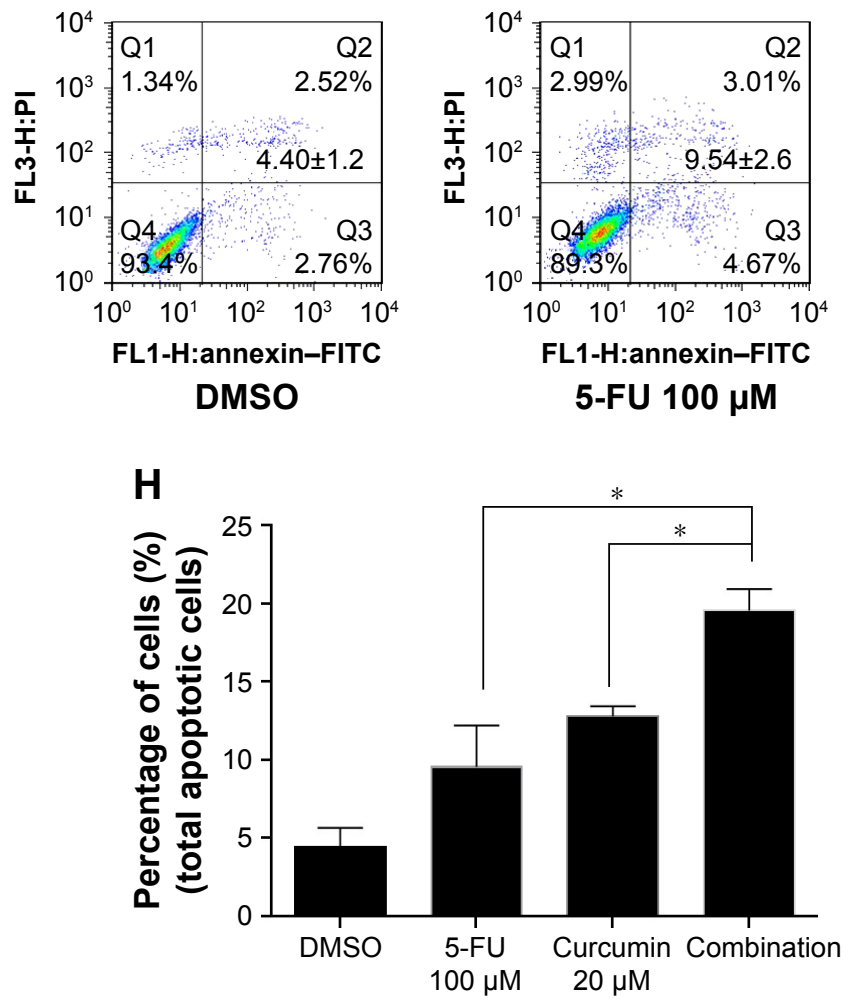

SGCR
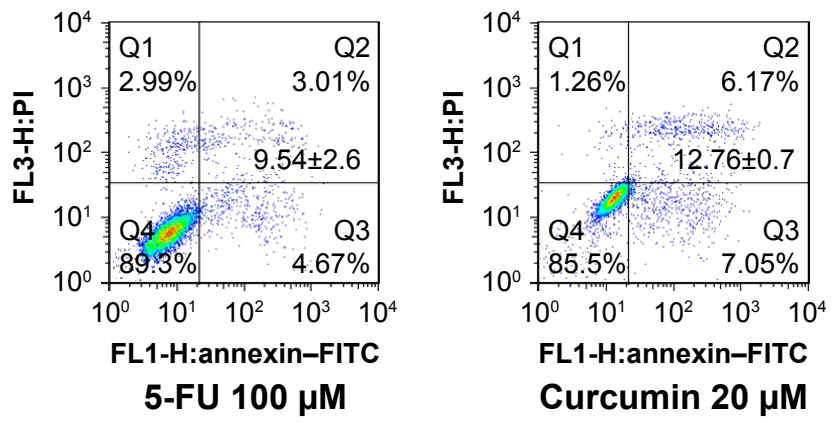

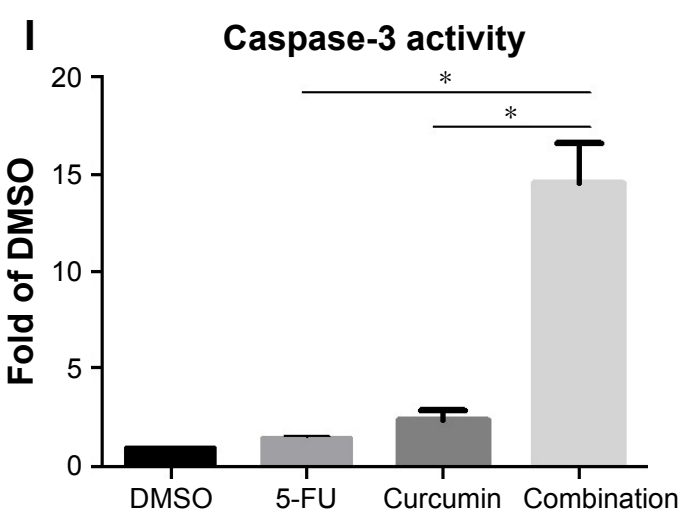

Figure 2 Combination of 5-FU and curcumin induces efficient apoptosis in SGCR cancer cells.

Notes: (A) SGCR cells were incubated with increasing doses of curcumin, 5-FU, or 5-FU + curcumin for 72 hours. Cell viability was determined by MTT assay and IC 50 values calculated. (B) Representative images of colony-formation assay with 5 -FU (20 $\mu$ M), curcumin $(2.5 \mu M)$, or the combination thereof. (C-F) SGCR cells were incubated with either $100 \mu \mathrm{M} 5$-FU, $20 \mu \mathrm{M}$ curcumin alone, or in combination for 24 hours. Whole-cell protein extracts were analyzed by Western blotting with the indicated antibodies. GAPDH antibody was used as the loading control. $* P<0.05 ; * P<0.01$. (G, H) SGCR cancer cells were treated with 5-FU, curcumin alone, or in combination (as indicated) for 48 hours, and cells were subsequently stained with fluorescein-conjugated annexin $\mathrm{V}$ and propidium iodide (PI) and analyzed by flow cytometry. All images are representative of three independent experiments. Data are mean \pm standard error of mean of three independent experiments. $* P<0.05$. (I) Caspase- 3 activity. Cells after treatment with 5 -FU $100 \mu \mathrm{M}$, curcumin $20 \mu \mathrm{M}$, or the combination thereof for 18 hours were lysed, and cell proteins were used to determine caspase-3 activity with an assay kit. $* P<0.05$.

Abbreviations: 5-FU, fluorouracil; IC ${ }_{50}$, half-maximal inhibitory concentration; DMSO, dimethyl sulfoxide; cl-PARP, cleaved PARP; FITC, fluorescein isothiocyanate.

confirmed that the NFKB signal-pathway activation was one of the major causes of resistance to 5-FU. Together, these observations indicate NFKB activation contributed at least in part to the survival of SGCR/5-FU cells in the presence of 5-FU. Curcumin disrupted NFKB activation and sensitized the 5-FU-resistant SGC cells.

\section{NFKB signaling is hyperactivated in the majority of clinical GC samples}

To determine further whether the NFKB-signaling pathway was active in clinical GC samples, we examined TNF $\alpha$ mRNA in tumor-tissue samples and the adjacent normal gastric epithelial cells from 32 patients using quantitative RT-PCR analysis. The results are presented in Figure 4A. TNF $\alpha$ mRNA was detected in about $65.6 \%$ of all GC samples. The results of Western blotting and immunohistochemistry analysis showed that $\mathrm{NF \kappa B}$ was more frequently activated in tumor samples than in normal gastric tissues
(Figure 4B and C). In clinical specimens, elevated NFKB activation was detected in nearly $60 \%$ of GCs. The results indicate that NFKB activation may play important roles in promoting tumor growth and chemotherapy resistance in clinical patients.

\section{Discussion}

Curcumin has long been known to act as a therapeutic or preventive agent for the treatment of several major human cancers involved in a variety of antitumor cellular processes. ${ }^{28,29}$ It has been found that curcumin by oral administration had beneficial effects on several types of premalignant lesions. In a recent Phase I clinical trial, curcumin combined with standard docetaxel chemotherapy produced significant biological improvements and clinical response in patients with metastatic breast cancer. ${ }^{19}$ Therefore, curcumin may have the potential as auxiliary treatment for other resistant cancers. We investigated whether curcumin could inhibit the 
activation of the NFKB survival-signaling pathway to reverse drug resistance to 5-FU and improve the efficacy in resistant GC cells. Our results showed that curcumin significantly sensitized GC cells to 5-FU treatment. SGC/5-FUR tumor cells exhibited remarkable sensitivities to curcumin-mediated apoptosis in vitro.

The underlying mechanisms for drug resistance to $5-\mathrm{FU}$ treatment for GC patients are still not clear. Drug resistance can be induced by the activation of survival-signaling pathways. The NFKB-signaling pathway is one of the most important survival-signaling cascades involved in drug resistance in tumor cells. NFKB signaling has been found to be important for the growth of antiestrogen-resistant breast cancer cells. ${ }^{30}$ Previous studies have also reported that the aberrant activation of NFKB signaling can induce drug resistance in cancer. ${ }^{31,32}$ For example, blockade of the NFKB-signaling pathway can overcome imatinib resistance. ${ }^{32}$ Therefore, we hypothesized that the NFKB-signaling pathway may be involved in drug-resistance development in GC. In order to verify our hypothesis, we developed 5-FU-resistant
A

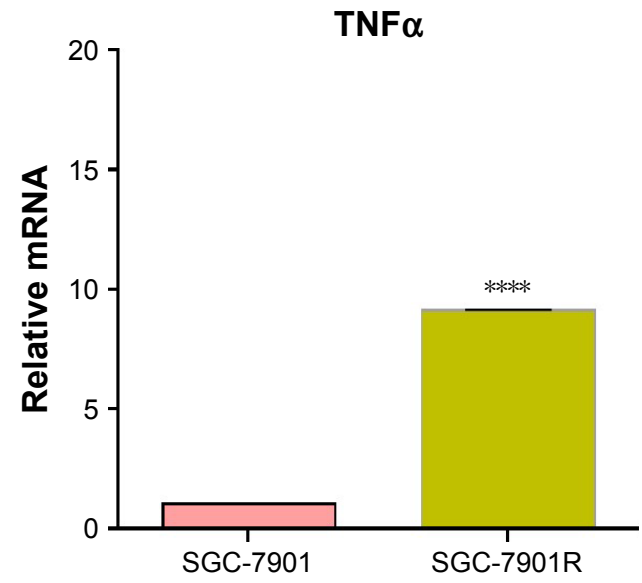

C

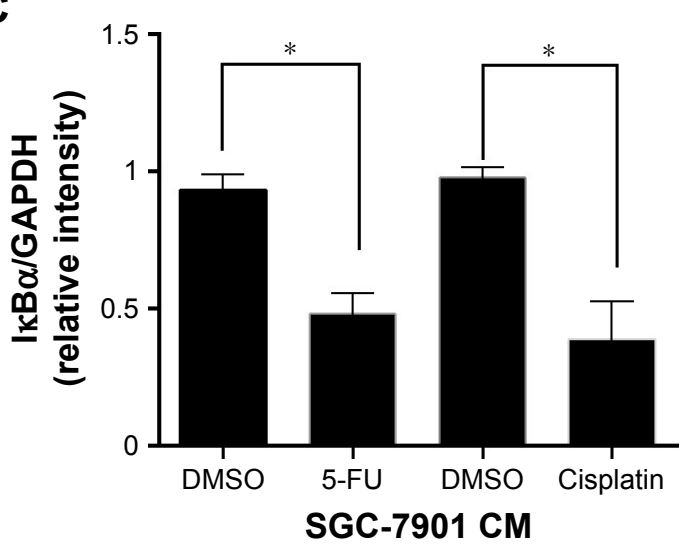

E

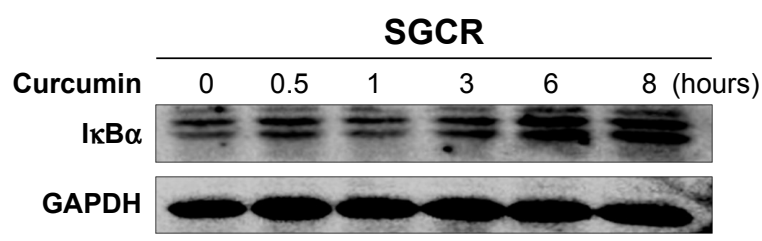

B

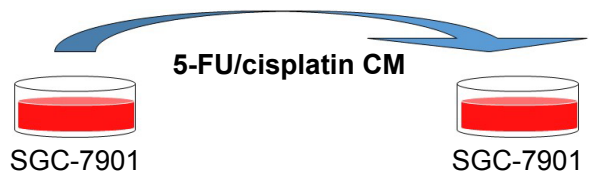

SGC-7901

$\mathrm{I} \kappa \mathrm{B} \alpha$

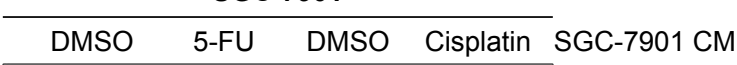

GAPDH
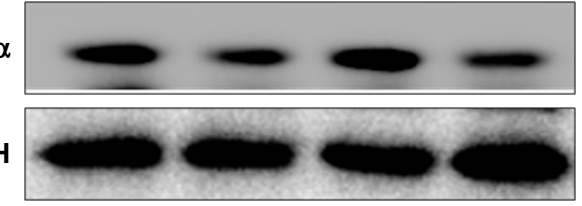

D

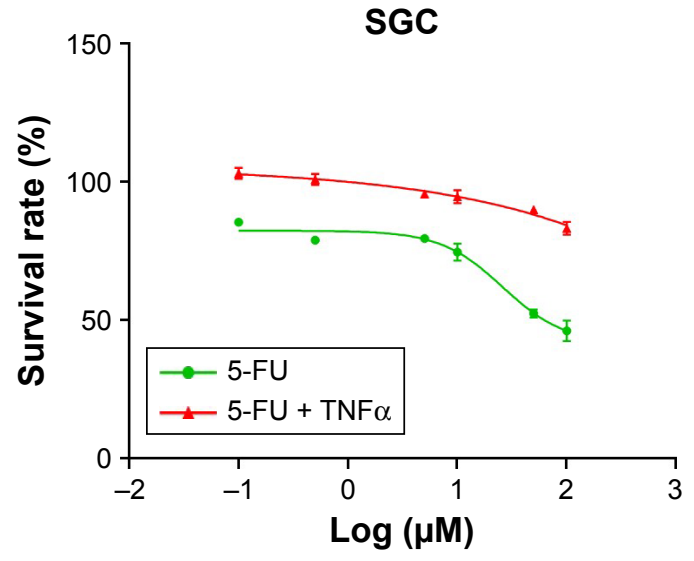

F

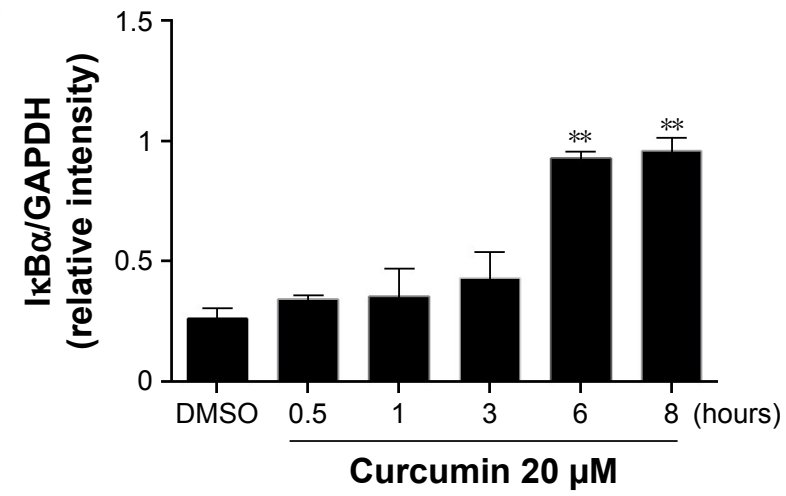

Figure 3 (Continued) 
G

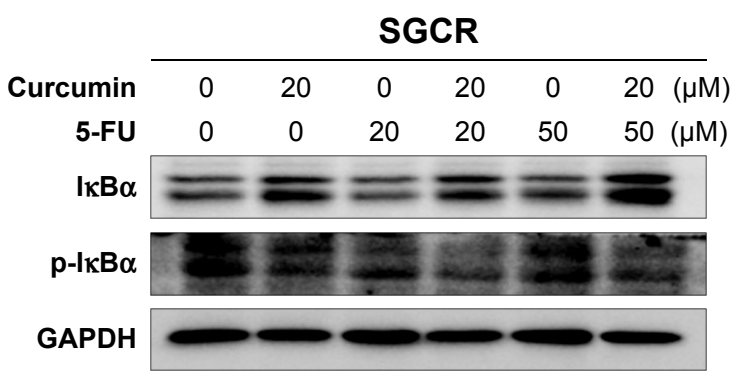

I

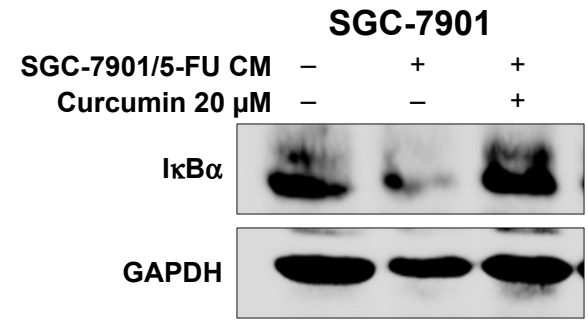

H

IKB $\alpha / G A P D H$

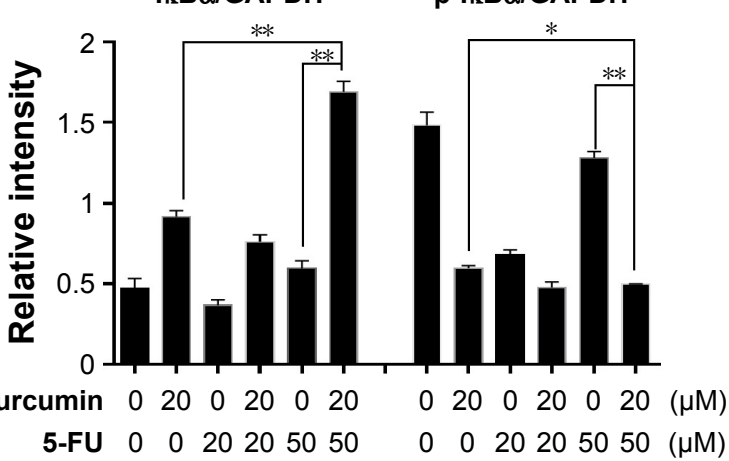

J

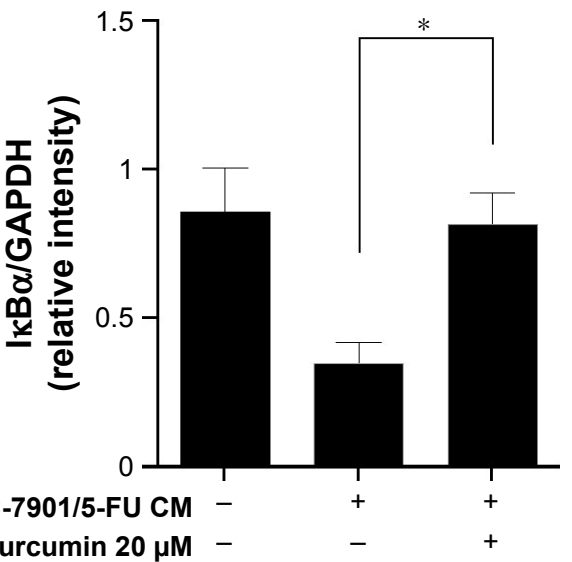

Figure 3 Curcumin disrupts the NFKB-signaling pathway.

Notes: (A) Total RNA extracted from the indicated cell lines was subjected to reverse-transcription and real-time PCR analysis of TNF $\alpha$ mRNA. Data were normalized by amount of GAPDH mRNA, and are presented as mean \pm standard error of mean from three independent experiments. (B, C) CM from SGC cells treated with DMSO, 5-FU, or cisplatin were incubated with the indicated SGC cell lines for 4 hours. IKB $\alpha$ was determined by Western blot. GAPDH served as a loading control. (D) Cells were treated for 72 hours with various concentrations of 5-FU in the absence or presence of TNF $\alpha(20 \mathrm{ng} / \mathrm{mL})$, and viability was assessed by MTT assay and normalized to TNF $\alpha$ treatment in the absence of drug. Data are means of triplicates from representative experiments and expressed as percentage survival. (E, F) SGCR cells treated with curcumin ( $20 \mu M$ ) at a series of time points; I $\mathrm{B} B \alpha$ expression was determined using immunoblot assay. $(\mathbf{G}, \mathbf{H})$ SGCR cells were incubated in a medium alone or a medium containing different

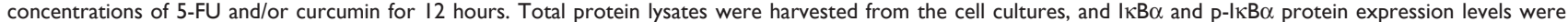
determined by Western blot analysis. (I, J) SGC cells were incubated in CM medium from SGC cells treated with 5-FU for 6 hours, then treated with curcumin (20 $\mu$ M) for 4 hours; I $\mathrm{KB} \alpha$ expression was determined using immunoblot assay. $* P<0.05 ; * * P<0.01$; $* * * * P<0.000$ I.

Abbreviations: PCR, polymerase chain reaction; mRNA, messenger RNA; CM, conditioned media; DMSO, dimethyl sulfoxide; 5-FU, fluorouracil; p-IKB $\alpha$, phosphorylated $I \kappa B \alpha$.

(SGCR/5-FU) cell lines and found marked activation of $\mathrm{NF} \kappa \mathrm{B}$ signaling in SGCR/5-FU cells. We have confirmed that $\mathrm{NF} \kappa \mathrm{B}$ signaling played a major role in the 5-FU resistance of GC cells. Importantly, hyperactivated NF $\kappa B$ was detected in clinical specimens from GC patients. Our results are in agreement with other reports that curcumin can suppress NFKB activation.

Therapy-induced tumor secretomes promote resistance and tumor progression. ${ }^{33}$ We further investigated the correlation between the level of cytokine TNF $\alpha$ and the NFאB activation that mediates GC resistance. Increasing TNF $\alpha$ has been found to induce translocation of p65 into the nucleus and reverse tamoxifen-resistant breast cancer cells. ${ }^{33}$ In our study, quantitative RT-PCR analysis revealed that TNF $\alpha$ was greatly increased in SGCR/5-FU cells compared with that in parental SGC cells. Treatment of sensitive SGC cells with CM-5-FU also activated the NFkB-signaling pathway. Such results suggest that cytokine TNF $\alpha$ was closely correlated to the abnormal activation of the NFKB-signaling pathway. We found that the increase in cytokine TNF $\alpha$ resulted from NF $\kappa$ B activation. Research has demonstrated that PI3Kdriven NF $\kappa$ B activation leads to increased activation of nearby stromal cells, helping to generate a protumor microenvironment and facilitate tumor progression. ${ }^{34}$ This research also indicated that $\mathrm{NF \kappa B}$ plays diverse roles downstream from different oncogenic signaling pathways. Therefore, targeting $\mathrm{NF} \kappa \mathrm{B}$ has been attracting more attention as a novel preventive and therapeutic strategy against refractory human cancers.

\section{Conclusion}

Our results demonstrated that activation of the NFKBsignaling pathway may be a possible mechanism for resistance of 5-FU in GC cells. We identified that curcumin, a safe oral drug, can reverse 5-FU resistance and inhibit proliferation in 

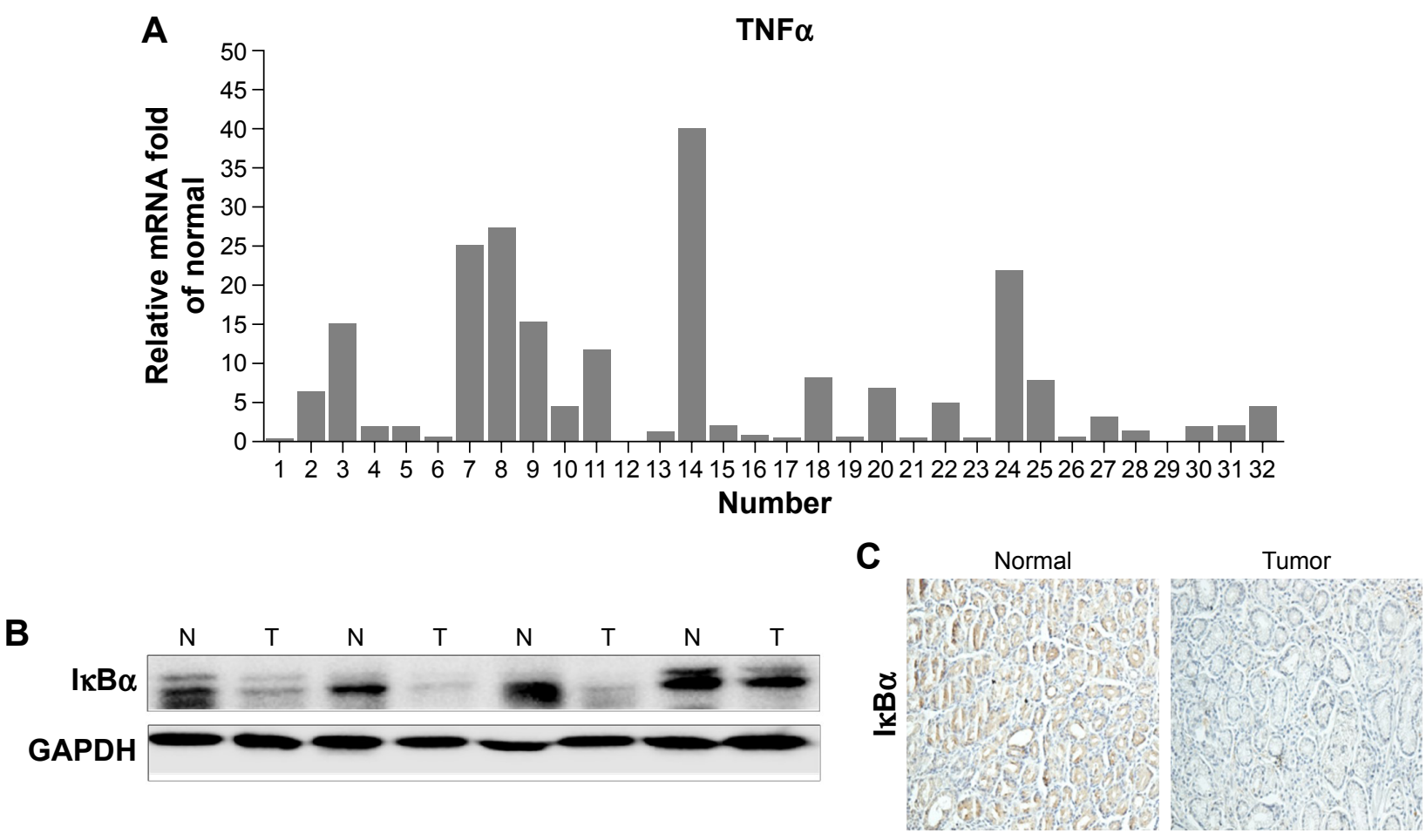

Figure 4 GC-tumor clinical samples.

Notes: (A) Expression levels of TNF $\alpha$ in tissues. TNF $\alpha$ mRNA in tumor-tissue samples and the adjacent normal gastric epithelial cells from 32 patients . It was about $65.6 \%$ of all GC samples expressed TNF $\alpha$ mRNA compared with normal tissues; (B, C) immunoblot analysis and immunohistochemical images of IKB $\alpha$ in tumor samples of GC patients or normal tissues. Tissue was counterstained with hematoxylin.

Abbreviations: GC, gastric cancer; mRNA, messenger RNA; N, Normal; T, Tumor.

GC cells by downregulating the NFKB-signaling pathway. Combination of curcumin and 5-FU resulted in synergistic antiproliferative effects and induced synergistically potent apoptosis in SGCR/5-FU cells. Our study provides a novel mechanism-based rationale for further animal experiments and clinical studies to confirm the combination therapy of curcumin and 5-FU in patients with GC.

\section{Acknowledgments}

This work was supported by the National Natural Science Funding program of China (21472142), Zhejiang Natural Science Funding (LY16H160052) and Medical Scientific Research Foundation of Zhejiang Province (2017192276). We thank Dr Huameng Li for helpful discussions and assistance in writing the manuscript.

\section{Disclosure}

The authors report no conflicts of interest in this work.

\section{References}

1. Siegel RL, Miller KD, Jemal A. Cancer statistics, 2015. CA Cancer J Clin. 2015;65(1):5-29.

2. Kim DC, Park KR, Jeong YJ, et al. Resistance to the c-Met inhibitor KRC-108 induces the epithelial transition of gastric cancer cells. Oncol Lett. 2016;11(2):991-997.

3. Holohan C, Van Schaeybroeck S, Longley DB, Johnston PG. Cancer drug resistance: an evolving paradigm. Nat Rev Cancer. 2013;13(10):714-726.
4. Subhash VV, Tan SH, Tan WL, et al. GTSE1 expression represses apoptotic signaling and confers cisplatin resistance in gastric cancer cells. BMC Cancer. 2015;15:550.

5. Park MH, Hong JT. Roles of NF- $\kappa B$ in cancer and inflammatory diseases and their therapeutic approaches. Cells. 2016;5(2):E15.

6. Wang D, Montgomery RB, Schmidt LJ, et al. Reduced tumor necrosis factor receptor-associated death domain expression is associated with prostate cancer progression. Cancer Res. 2009;69(24): 9448-9456.

7. Wu T, Dai Y. Tumor microenvironment and therapeutic response. Cancer Lett. Epub 2016 Feb 1.

8. Li S, Wang N, Brodt P. Metastatic cells can escape the proapoptotic effects of TNF- $\alpha$ through increased autocrine IL-6/STAT3 signaling. Cancer Res. 2012;72(4):865-875.

9. Müerköster S, Arlt A, Witt M, et al. Usage of the NF- $\kappa B$ inhibitor sulfasalazine as sensitizing agent in combined chemotherapy of pancreatic cancer. Int J Cancer. 2003;104(4):469-476.

10. Zeng C, Zhong P, Zhao Y, et al. Curcumin protects hearts from FFAinduced injury by activating $\mathrm{Nrf} 2$ and inactivating NF- $\mathrm{\kappa B}$ both in vitro and in vivo. $J$ Mol Cell Cardiol. 2015;79:1-12.

11. Compagno M, Lim WK, Grunn A, et al. Mutations of multiple genes cause deregulation of NF- $\mathrm{kB}$ in diffuse large B-cell lymphoma. Nature. 2009;459(7247):717-721.

12. Kodela R, Nath N, Chattopadhyay M, Nesbitt DE, VelázquezMartínez CA, Kashfi K. Hydrogen sulfide-releasing naproxen suppresses colon cancer cell growth and inhibits NF-KB signaling. Drug Des Devel Ther. 2015;9:4873-4882.

13. Flynn V Jr, Ramanitharan A, Moparty K, et al. Adenovirus-mediated inhibition of NF- $\mathrm{KB}$ confers chemo-sensitization and apoptosis in prostate cancer cells. Int J Oncol. 2003;23(2):317-323.

14. Li M, Zhang Z, Hill DL, Wang H, Zhang R. Curcumin, a dietary component, has anticancer, chemosensitization, and radiosensitization effects by down-regulating the MDM2 oncogene through the PI3K/ mTOR/ETS2 pathway. Cancer Res. 2007;67(5):1988-1996. 
15. Narasimhan M, Ammanamanchi S. Curcumin blocks RON tyrosine kinase-mediated invasion of breast carcinoma cells. Cancer Res. 2008; 68(13):5185-5192.

16. Xiao J, Sheng X, Zhang X, Guo M, Ji X. Curcumin protects against myocardial infarction-induced cardiac fibrosis via SIRT1 activation in vivo and in vitro. Drug Des Devel Ther. 2016;10:1267-1277.

17. Koo JY, Kim HJ, Jung KO, Park KY. Curcumin inhibits the growth of AGS human gastric carcinoma cells in vitro and shows synergism with 5-fluorouracil. J Med Food. 2004;7(2):117-121.

18. Pandey A, Vishnoi K, Mahata S, et al. Berberine and curcumin target survivin and STAT3 in gastric cancer cells and synergize actions of standard chemotherapeutic 5-fluorouracil. Nutr Cancer. 2015;67(8): 1293-1304.

19. Bayet-Robert M, Kwiatkowski F, Leheurteur M, et al. Phase I dose escalation trial of docetaxel plus curcumin in patients with advanced and metastatic breast cancer. Cancer Biol Ther. 2010;9(1):8-14.

20. Mahammedi H, Planchat E, Pouget M, et al. The new combination docetaxel, prednisone and curcumin in patients with castration-resistant prostate cancer: a pilot phase ii study. Oncology. 2016;90(2):69-78.

21. Ware KE, Hinz TK, Kleczko E, et al. A mechanism of resistance to gefitinib mediated by cellular reprogramming and the acquisition of an FGF2-FGFR1 autocrine growth loop. Oncogenesis. 2013;2:e39.

22. Obenauf AC, Zou Y, Ji AL, et al. Therapy-induced tumour secretomes promote resistance and tumour progression. Nature. 2015;520(7547): 368-372.

23. Kunnumakkara AB, Guha S, Krishnan S, Diagaradjane P, Gelovani J, Aggarwal BB. Curcumin potentiates antitumor activity of gemcitabine in an orthotopic model of pancreatic cancer through suppression of proliferation, angiogenesis, and inhibition of nuclear factor- $\kappa \mathrm{B}-$ regulated gene products. Cancer Res. 2007;67(8):3853-3861.

24. Yang J, Lin Y, Guo Z, et al. The essential role of MEKK3 in TNFinduced NF- $\kappa \mathrm{B}$ activation. Nat Immunol. 2001;2(7):620-624.
25. Bao C, Li Y, Huan L, et al. NF- $\mathrm{KB}$ signaling relieves negative regulation by miR-194 in hepatocellular carcinoma by suppressing the transcription factor HNF-1 $\alpha$. Sci Signal. 2015;8(387):ra75.

26. Camargo RG, Riccardi DM, Ribeiro HQ, et al. NF-кB p65 and expression of its pro-inflammatory target genes are upregulated in the subcutaneous adipose tissue of cachectic cancer patients. Nutrients. 2015;7(6): 4465-4479.

27. Bivona TG, Hieronymus $\mathrm{H}$, Parker $\mathrm{J}$, et al. FAS and NF- $\kappa \mathrm{B}$ signalling modulate dependence of lung cancers on mutant EGFR. Nature. 2011; 471(7339):523-526.

28. Bimonte S, Barbieri A, Leongito M, et al. Curcumin anticancer studies in pancreatic cancer. Nutrients. 2016;8(7):E433.

29. Charpentier MS, Whipple RA, Vitolo MI, et al. Curcumin targets breast cancer stem-like cells with microtentacles that persist in mammospheres and promote reattachment. Cancer Res. 2014;74(4):1250-1260.

30. Yde CW, Emdal KB, Guerra B, Lykkesfeldt AE. NF $\mathrm{BB}$ signaling is important for growth of antiestrogen resistant breast cancer cells. Breast Cancer Res Treat. 2012;135(1):67-78.

31. Dai Y, Lawrence TS, Xu L. Overcoming cancer therapy resistance by targeting inhibitors of apoptosis proteins and nuclear factor-kappa B. Am J Transl Res. 2009;1(1):1-15.

32. Cilloni D, Messa F, Arruga F, et al. The NF- $\kappa B$ pathway blockade by the IKK inhibitor PS1145 can overcome imatinib resistance. Leukemia. 2006;20(1):61-67.

33. Lundqvist J, Yde CW, Lykkesfeldt AE. 1 $\alpha, 25$-Dihydroxyvitamin D3 inhibits cell growth and NFKB signaling in tamoxifen-resistant breast cancer cells. Steroids. 2014;85:30-35.

34. Hutti JE, Pfefferle AD, Russell SC, Sircar M, Perou CM, Baldwin AS. Oncogenic PI3K mutations lead to NF-KB-dependent cytokine expression following growth factor deprivation. Cancer Res. 2012;72(13): 3260-3269.
OncoTargets and Therapy

\section{Publish your work in this journal}

OncoTargets and Therapy is an international, peer-reviewed, open access journal focusing on the pathological basis of all cancers, potential targets for therapy and treatment protocols employed to improve the management of cancer patients. The journal also focuses on the impact of management programs and new therapeutic agents and protocols on

\section{Dovepress}

patient perspectives such as quality of life, adherence and satisfaction The manuscript management system is completely online and includes a very quick and fair peer-review system, which is all easy to use. Visit http://www.dovepress.com/testimonials.php to read real quotes from published authors. 